\title{
Spontaneous firing activity in climbing fiber is critical for a realistic bi-hemispherical cerebellar neuronal network during robot control
}

\author{
Ruben-Dario Pinzon-Morales, Yutaka Hirata* \\ From The Twenty Third Annual Computational Neuroscience Meeting: CNS*2014 \\ Québec City, Canada. 26-31 July 2014
}

\begin{abstract}
Introduction
The cerebellum plays a crucial role in short-term motor learning, sensory-motor transformations, and cognitive functioning [1,2]. In motor control and learning, the cerebellum adaptively accounts for development, aging, injuries all that may cause asymmetries in neuromuscular and optical properties [3]. Previously we have configured a physio-anatomically inspired bi-hemispherical cerebellar neuronal network (biCNN), and demonstrated that the biCNN can govern an unstable 2-wheeled balancing robot under asymmetrical perturbation conditions [4]. Exalted by observations of bilateral plasticity during unilateral learning paradigms $[3,5,6]$, right and left hemispheres of the cerebellum were separately modeled in the biCNN. Each hemisphere included granular (Gr), Golgi (Go), basket/stellate (Ba/St), and Purkinje (Pk) cells. Excitatory inputs to the biCNN carried by mossy fibers (mfs) provided the desired motion trajectories. Inhibitory feedback loop between $\mathrm{Gr}$ and Go, and feed-forward inhibitory loop between $\mathrm{Ba} / \mathrm{St}$ and $\mathrm{Pk}$ were also included. The teaching signal to the Pk via climbing fibers (cf) was implemented to include the very low spontaneous spike activity ( $\sim 1$ spikes/s) observed in this fiber [5,6]. A proportional and differential (PD) controller sharing the same mfs inputs was introduced to represent the non-cerebellar input to the vestibular nucleus $(\mathrm{Vn})$. The $\mathrm{Vn}$ computed the arithmetic difference between the PD and the Pk cells output and produced the motor command to the robot. The error signal originated from the concurrent PD controller was split into two by using half-wave rectifiers. The negative and positive waves, akin the forward and backward
\end{abstract}

\footnotetext{
* Correspondence: yutaka@isc.chubu.ac.jp

Department of Computer Science, Chubu University Graduate School of Engineering, Kasugai, 487-8501, Japan
}

\section{Methods}

Firstly, an inhibitory input to Go cells via Lugaro (Lu) cells was implemented [8]. Secondly, the number of neuron models in each hemisphere was increased (from 1.500 to 20.000) to better reflect the ratio of neurons in the real cerebellum [1]. Each hemisphere comprised $128 \mathrm{mf}, 9956 \mathrm{Gr}, 15 \mathrm{Go}, 300 \mathrm{Ba} / \mathrm{St}, 3 \mathrm{Lu}$, and $30 \mathrm{Pk}$ cells. Thirdly, mutual inhibitory synapses between Pk cell and $\mathrm{Ba} / \mathrm{St}$ was included, and finally a simple learning rule governing the $\mathrm{Pk}-\mathrm{Vn}$ synaptic plasticity was implemented [1]. The robot was commanded to follow a sinusoidal $(\mathrm{f}=$ $0.25 \mathrm{~Hz}$ ) wheel motion for 200 cycles. At cycle 100, an

\section{Results}

Results showed that asymmetrical perturbations to the robot were successfully handled by the biCNN, and that the spontaneous activity in the $\mathrm{cf}$ was critical for balancing the contribution of the cerebellar hemispheres to the Vn. Disabling the spontaneous activity endangered the biCNN output during the asymmetrical robot control scenario.

\section{Conclusions}

In our robot control framework, the cf input carrying spontaneous activity drove the learning in the two hemispheres 
of the biCNN required to control the unstable robot during asymmetrical perturbations.

Published: 21 July 2014

\section{References}

1. Ito M: Cerebellar circuitry as a neuronal machine. Prog Neurobiol 2006, 78(3-5):272-303.

2. De Zeeuw $\mathrm{Cl}$, et al: Spatiotemporal firing patterns in the cerebellum. Nat Rev Neurosci 2011, 12(6):327-344.

3. Demer JL: Mechanisms of human vertical visual-vestibular interaction J Neurophysiol 1992, 68(6):2128-46.

4. Pinzon-Morales R-D, et al: Adaptive control of 2-wheeled balancing robot by two hemispheric cerebellar neuronal network model. BMC Neurosci 2012, 13(Suppl 1):118.

5. Wulff $P$, et al: Synaptic inhibition of Purkinje cells mediates consolidation of vestibulo-cerebellar motor learning. Nat Neurosci 2009, 12(8):1042-1049.

6. Hirata $Y$, et al: Flocculus Purkinje cell complex spikes during acute motor learning of the horizontal vestibuloocular reflex in squirrel monkeys. Soc. Neurosci Abstr 2006, Program No. 805.6.

7. Ito M, Kano M: Long-lasting depression of parallel fiber-Purkinje cell transmission induced by conjunctive stimulation of parallel fibers and climbing fibers in the cerebellar cortex. Neurosci Lett 1982, 33(3):253-258.

8. Lainé J, Axelrad H: Morphology of the Golgi-impregnated Lugaro cell in the rat cerebellar cortex: a reappraisal with a description of its axon. J Comp Neurol 1996, 375(4):618-40.

doi:10.1186/1471-2202-15-S1-P142

Cite this article as: Pinzon-Morales and Hirata: Spontaneous firing activity in climbing fiber is critical for a realistic bi-hemispherical cerebellar neuronal network during robot control. BMC Neuroscience 2014 15(Suppl 1):P142.

\section{Submit your next manuscript to BioMed Central} and take full advantage of:

- Convenient online submission

- Thorough peer review

- No space constraints or color figure charges

- Immediate publication on acceptance

- Inclusion in PubMed, CAS, Scopus and Google Scholar

- Research which is freely available for redistribution

Submit your manuscript at www.biomedcentral.com/submit
Biomed Central 